\title{
The Effect of Machining Parameters on the Cutting Forces, Tool Wear, and Machined Surface Roughness of Metal Matrix Nano Composite Material
}

\author{
E. Y. El-Kady ${ }^{1}$, A. M. Gaafer ${ }^{1}$, M. H. G. Ghaith ${ }^{2}$, T. Khalil ${ }^{1}$, A. A. Mostafa ${ }^{1}$ \\ ${ }^{1}$ Benha University, Faculty of Engineering at Shoubra, Cairo, Egypt \\ ${ }^{2}$ King Khalid University (KKU), Department of Mechanical Engineering, Abha, Kingdom of Saudi Arabia (KSA)
}

To cite this article:

E. Y. El-Kady, A. M. Gaafer, M. H. G. Ghaith, T. Khalil, A. A. Mostafa. The Effect of Machining Parameters on the Cutting Forces, Tool Wear, and Machined Surface Roughness of Metal Matrix Nano Composite Material. Advances in Materials. Vol. 4, No. 3, 2015 , pp. 43-50. doi: $10.11648 /$ j.am.20150403.11

\begin{abstract}
The aim of the present study is to investigate the effect of machining parameters on the cutting forces, tool wear, and machined surface roughness of metal matrix nano composite material through dry turning operations. Composites specimens manufactured from aluminum alloy metal matrix and reinforced with different weight fractions of silicon carbide nano particulates were used to conduct the experimental work. Stir-casting method followed by squeezing technique were used to fabricate the nano composites specimens. The machinability tests were conducted through different cutting conditions using carbide inserts tools material. The machinability characteristics such as surface roughness of the machined specimens, types of chip, cutting forces in the direction of main cutting motion, and tool wear were investigated through the experimental conditions. The results showed improve in surface roughness by increasing the cutting speed and the weight fraction percent of the $\mathrm{SiC}$ nanoparticulates. On the other hand the main cutting force component as well as tool flank wear were increased by increasing the weight fraction of $\mathrm{SiC}$ nanoparticulates. Moreover the force component increased with increasing the feed rate and depth of cut, however the cutting forces were decreased by increasing the cutting speed while the flank wear increase.
\end{abstract}

Keywords: Nano-Composites, Machining parameters, Cutting Forces, Tool Wear, Types of Chip, Surface Roughness

\section{Introduction}

Composite materials are one of the most interesting groups of materials as light and strong materials are very attractive for applications in different industries. MMCs tailor the best properties of the two components, such as ductility and toughness of the matrix and high modulus and strength of the reinforcements. [1] Particle reinforced composites are more attractive than fiber reinforced composites, this is due to their cost-effectiveness, isotropic properties, and their ability to be processed using similar technology used for monolithic materials. [2] It was found that the mechanical properties of nano-particle dispersion strengthened MMCs are far superior to those of micrometric dispersion strengthened MMCs with a similar volume composition of particulate. [3] The improved properties of composites increased the requirement of replacing the traditional alloys with them. Although casting as a fabrication process produces the required net shape, yet machining process are required to produce the exact required tolerances and dimensions of products.
Although many studies were done on the machinability of microsize particle reinforced composites [4-8], however only small studies were done on the machinability of nanosize particle reinforced composites. Turning, milling and drilling are the most common operations that are being done on composites. In this work dry turning operations were done on conventional turning machine and the main cutting forces, surface roughness, tool wear and chip appearance were investigated.

\section{Experimental Procedure}

An Aluminum-silicon cast alloy of high percentage of silicon to improve castability was used as a matrix the chemical composition of the alloy is shown in TABLE 1. SiC nanoparticulates were used as reinforcement. Several composites specimens were prepared with different weight fractions of $\mathrm{SiC}$ nanoparticulates which are 1\%, 2\%, 3\%, 4\% and $5 \%$. 
Table 1. The Chemical composition of the Al-Si Cast Alloy

\begin{tabular}{lllllllllll}
\hline Alloying Element & $\mathbf{S i}$ & $\mathbf{F e}$ & $\mathbf{C u}$ & $\mathbf{M n}$ & $\mathbf{M g}$ & $\mathbf{Z n}$ & $\mathbf{T i}$ & $\mathbf{N i}$ & $\mathbf{S n}$ & $\mathbf{A l}$ \\
\hline Wt. \% & 12 & 0.58 & 0.05 & 0.01 & 0.03 & 0.02 & 0.03 & 0.04 & 0.01 & Bal. \\
\hline
\end{tabular}

In the present work, an aluminum-silicon alloy (cast aluminum alloy) is used as matrix this due to the wide applications of aluminum-silicon alloys as they comprise $85 \%$ to $90 \%$ of the total aluminum cast parts produced for the automotive industry. Silicon carbide particles of nanoscale size were selected as a reinforcement material. Borax also known as sodium borate was used for washing the reinforcement to improve the wettability with the aluminum matrix, soap was added to the melt for degassing. Metal matrix composites specimens including various weight fractions 1,2, 3, 4 and 5 wt. \% of silicon carbide ( $\mathrm{SiC}$ ) nano-particulates of average size $200 \mathrm{~nm}$ were produced by liquid metallurgy method. The composites were fabricated by melting the matrix alloy using an electric furnace which employs resistance heating coils for generating the heat necessary for the melting process of maximum temperature of $1200^{\circ} \mathrm{C}$. Pieces of approximately 0.6 $\mathrm{kg}$ of the cast aluminum alloy were cut of a15 $\mathrm{Kg}$ ingot then, charged into the crucible made of graphite and the matrix alloy is heated up to $750 \pm 10^{\circ} \mathrm{C}$. When the melting temperature reached $750 \quad \pm 10 \quad{ }^{\circ} \mathrm{C}$ the preheated reinforcement nanoparticulates were gradually added to the molten alloy. A mixer was used to stir the molten alloy at approximately 400 $\mathrm{rev} / \mathrm{min}$ speed. The mixer is fed up and down inside the crucible to improve the distribution of the reinforcement particulates through the molten matrix. After complete mixing of the reinforcement with the matrix the mixture is poured into a tool steel die of $50 \mathrm{~mm}$ diameter and $120 \mathrm{~mm}$ depth. The die bore was coated with graphite powder to prevent the adhesion between the composite and die. The mold was preheated to $400 \pm 10 \mathrm{oC}$ before pouring the mixture in it. After pouring the molten mixture into the die, the die is closed by a fitted ram made of tool steel designed for compressing purposes. Compressive load of 35 ton from a 50 tons maximum capacity hydraulic press is gradually applied on the ram. When the compression load reach the required value it is held constant for 15 minutes to produce a uniform pressure distribution throughout the mixture. The mixture is left to solidify against the applied pressure and then the composite is then ejected from the die. This applied load was performed in order to prevent the grain growth during solidification as well as

reduces the shrink cavities and porosity. Olympus Optical microscope was employed to study the microstructure of the prepared composites. Hardness of composites of different weight fractions were measured and plotted. Machining tests were carried out on dry cutting conditions using a conventional center lathe. Carbide inserts supplied by KORLOY of code CCGT09T304 - AK had been used for conducting the machining tests. The tests were conducted at several cutting speeds of $49.9 \mathrm{~m} / \mathrm{min}, 70.8 \mathrm{~m} / \mathrm{min}, 99 \mathrm{~m} / \mathrm{min}, 139 \mathrm{~m} / \mathrm{min}$, $196.6 \mathrm{~m} / \mathrm{min}$ and $274.4 \mathrm{~m} / \mathrm{min}$, feed rates of $0.08 \mathrm{~mm} / \mathrm{rev}$. followed by $0.14 \mathrm{~mm} / \mathrm{rev}$. and ends by $0.2 \mathrm{~mm} / \mathrm{rev}$ finally several value of depth of cut of $0.75 \mathrm{~mm}, 1.5 \mathrm{~mm}$ and finally $2.25 \mathrm{~mm}$. The main cutting force component, tool flank wear, and surface roughness were measured for each test. The test results were plotted. The main cutting force component was measured using kistler dynamometer type 9257BA SN1492352 Figure 1. The main cutting force component was recorded directly using DynoWare software provided by the dynamometer manufacturer. The surface roughness measurement were carried out using Talysurf of commercial name (TAYLOR - HOBSON) Figure 2.

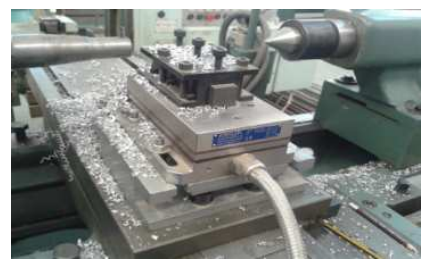

Figure 1. Kistler dynamometer

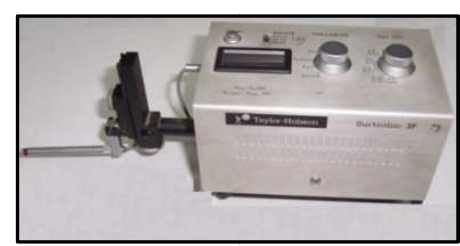

Figure 2. Taylor-Hobson Talysurf

\section{Results and Discussion}

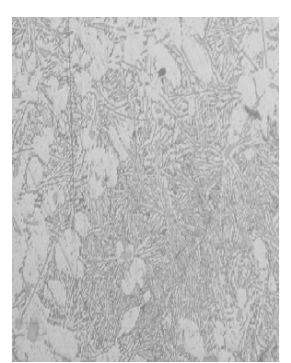

$1 \%$

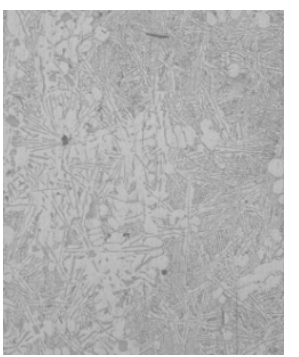

$2 \%$

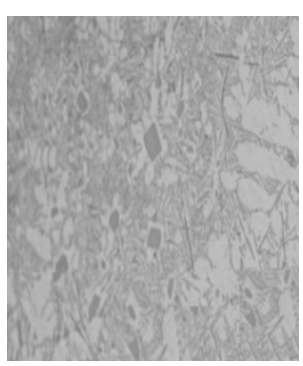

$3 \%$

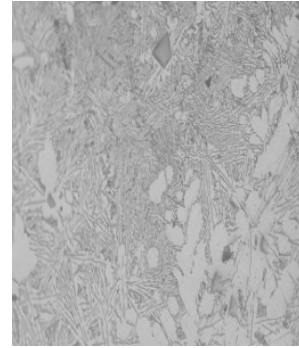

$4 \%$

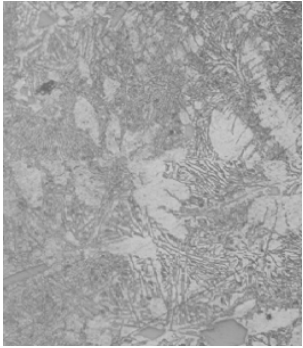

$5 \%$

Figure 3. Optical micrographs 


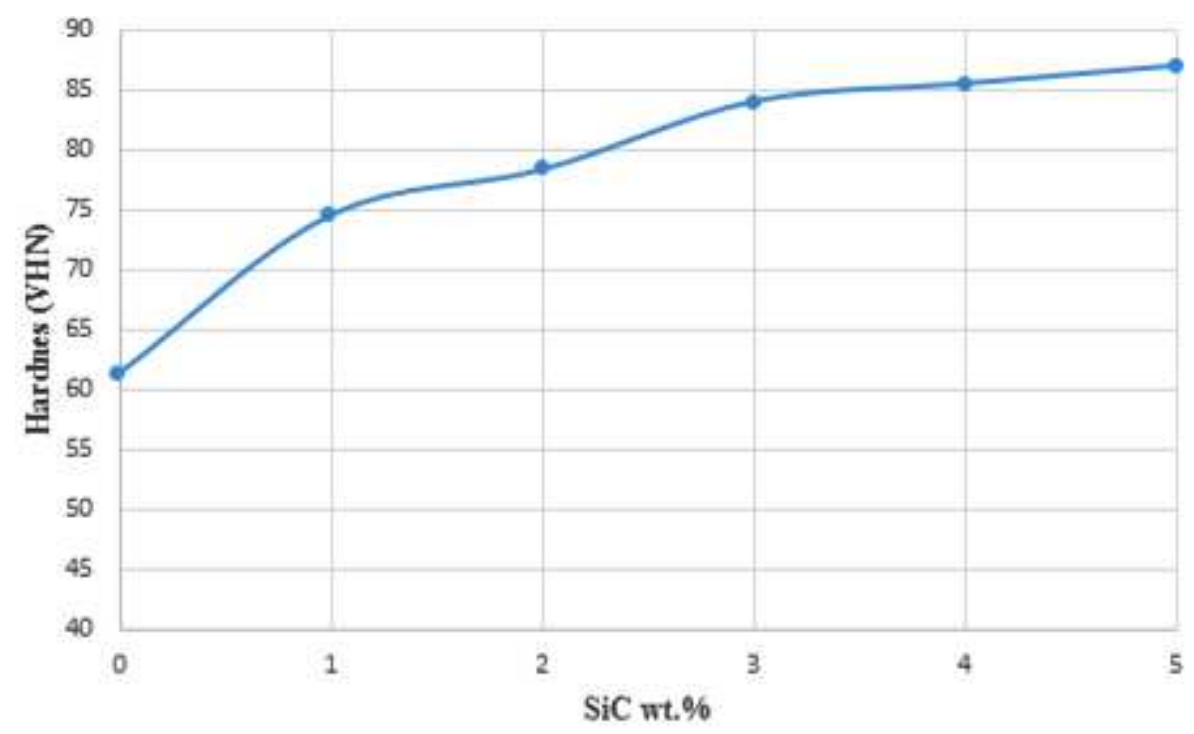

Figure 4. The effect of $\mathrm{SiC}$ weight fraction on the hardness of nanocomposites.

\subsection{Microstructure of Composites}

The optical microscope with magnification 10Xwas used to study the microstructure of composite specimens for different weight percent of $\mathrm{SiC}$ nanoparticulates. The obtained results are shown in figure 3 . From these figures it can be noticed that the structure of nanocomposite consists of primary $\alpha$ phase which appear as light areas. The Al-Si eutectic structure appears as a gray area and the shrink cavities appears as black areas. Clusters of $\mathrm{SiC}$ nanoparticulates are located inside the $\alpha$ phase as well as near the eutectic structure. Also, it has been observed that increasing the weight fraction of nanoparticulates dispersed inside the Aluminum-silicon alloy increases the agglomeration percent.

\subsection{Hardness Measurements}

The effect of the increase in the weight fraction of $\mathrm{SiC}$ in the nanocomposites can be understood from figure 4. It can be observed that the hardness of the composite specimens increases with the increase of volume fraction of $\mathrm{SiC}$ nanoparticulates. This is due to the increase of hard phase which is $\mathrm{SiC}$ nanoparticulates (reinforcement) and decrease of ductile phase which is the aluminum alloy (matrix).

\subsection{Cutting Forces Measurements}

The measurement of cutting forces is highly essential to analyze more effectively the machinability. Figure 4 shows the effect of the percentage weight fraction of $\mathrm{SiC}$ nanoparticulates on main cutting force component. It was noticed that (at the same feed, depth of cut and speed) a slight increase in the values of the main cutting forces component was recorded for the nanocomposites containing 1 wt. $\%, 2$ wt. $\%, 3$ wt. $\%, 4$ wt. $\%$ and 5 wt. $\%$ of $\mathrm{SiC}$ nanoparticulates such behavior may is attributed to the effect of the presence of hard reinforcements. Where the hardness and the strength of the nanocomposites increases with the increase of the reinforcement weight fraction.

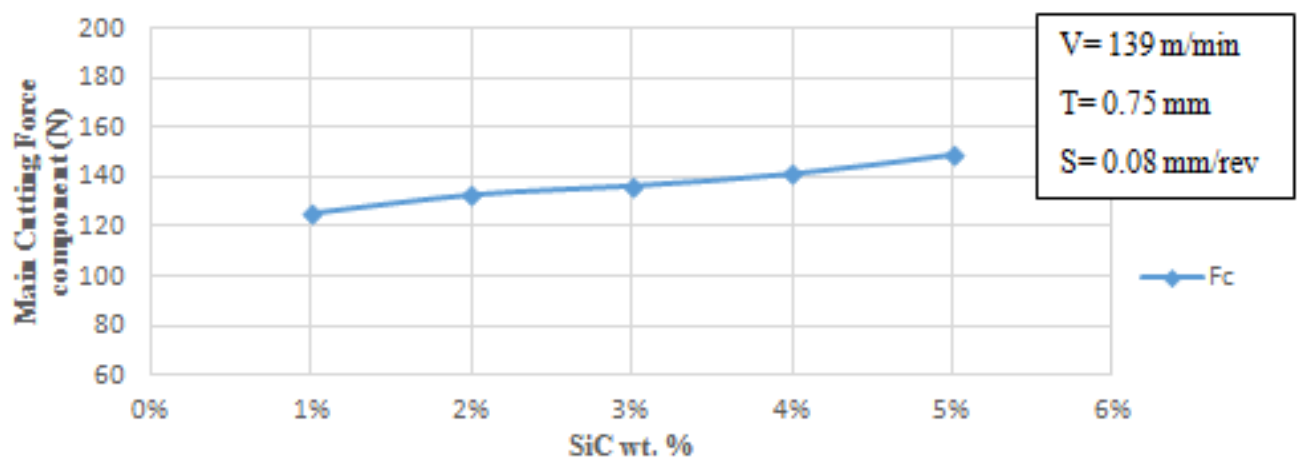

Figure 5. Shows the effect of the percentage weight fraction of SiC nanoparticulates on main cutting force component.

Figure 6 show the influence of cutting speed on the main cutting force component at certain values of the depth of cut and feed rate which are: $\mathrm{t}=2.25 \mathrm{~mm}, \mathrm{~s}=0.2 \mathrm{~mm} / \mathrm{rev}$, from these figures it can be observed that the main cutting force component was decreased by increasing cutting speed during turning of $\mathrm{Al} / \mathrm{SiC}$ nanocomposites. These results were attributed to the formation of built up edge (B.U.E) at low cutting speed i.e. from $50 \mathrm{~m} / \mathrm{min}$ to $90 \mathrm{~m} / \mathrm{min}$ and it disappears at high cutting speed. The BUE is a hardened element that will affect the shear angle and therefore increase 
the cutting forces. Since it is harder than the initial material, increase the cutting forces. [4, 9] it will be acting as an abrasive grain and will somehow

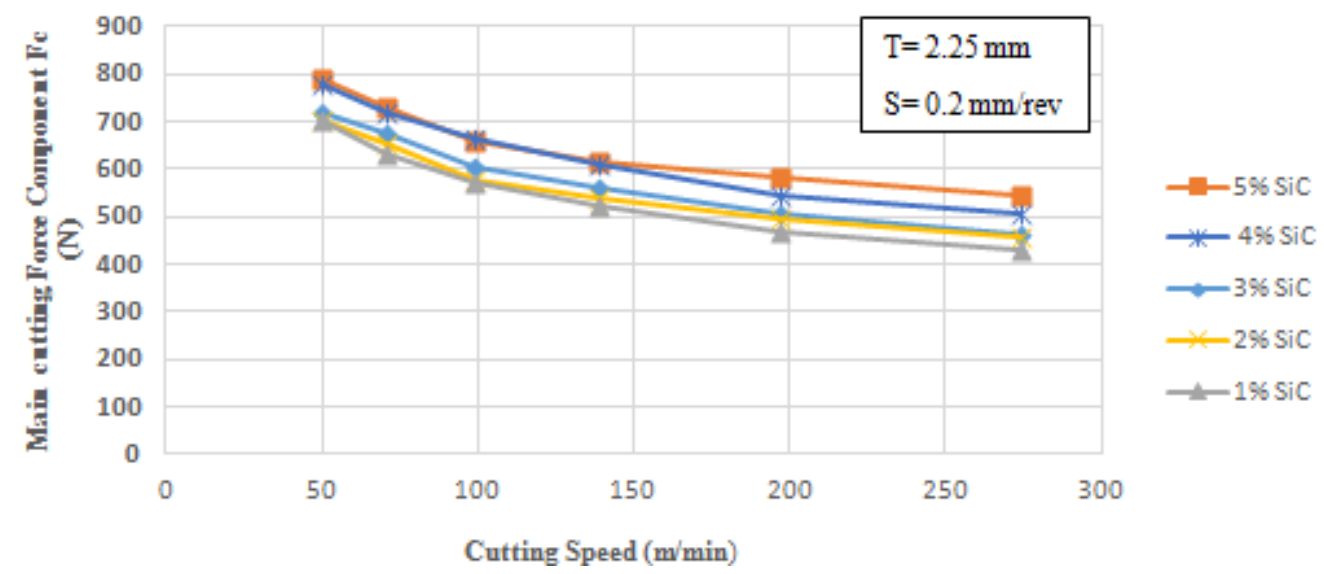

Figure 6. Show the influence of cutting speed on the main cutting force component.

The effect of feed rate on the main cutting force component is shown in the figures 7 from the figure it can be noticed that the main cutting force component was increased on increasing the feed rate which is due to the increase in contact area between the tool and work piece and thus the friction forces which are to be overcome by the tool.

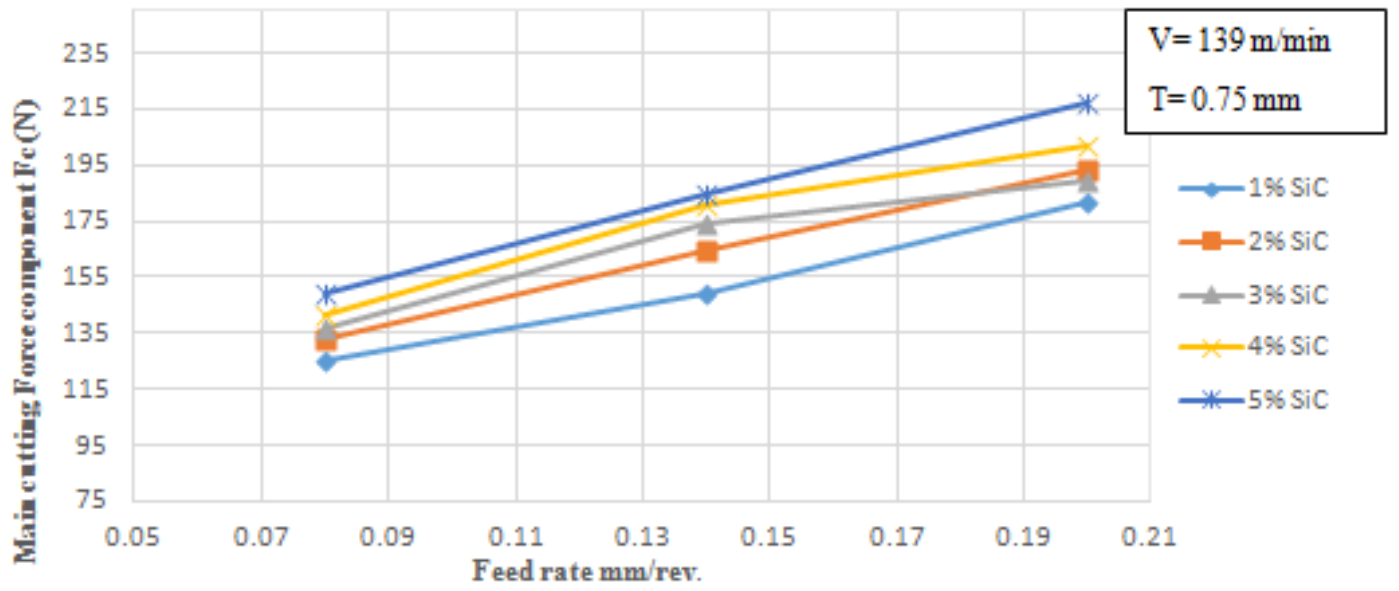

Figure 7. Shows the effect of feed rate on the main cutting force component.

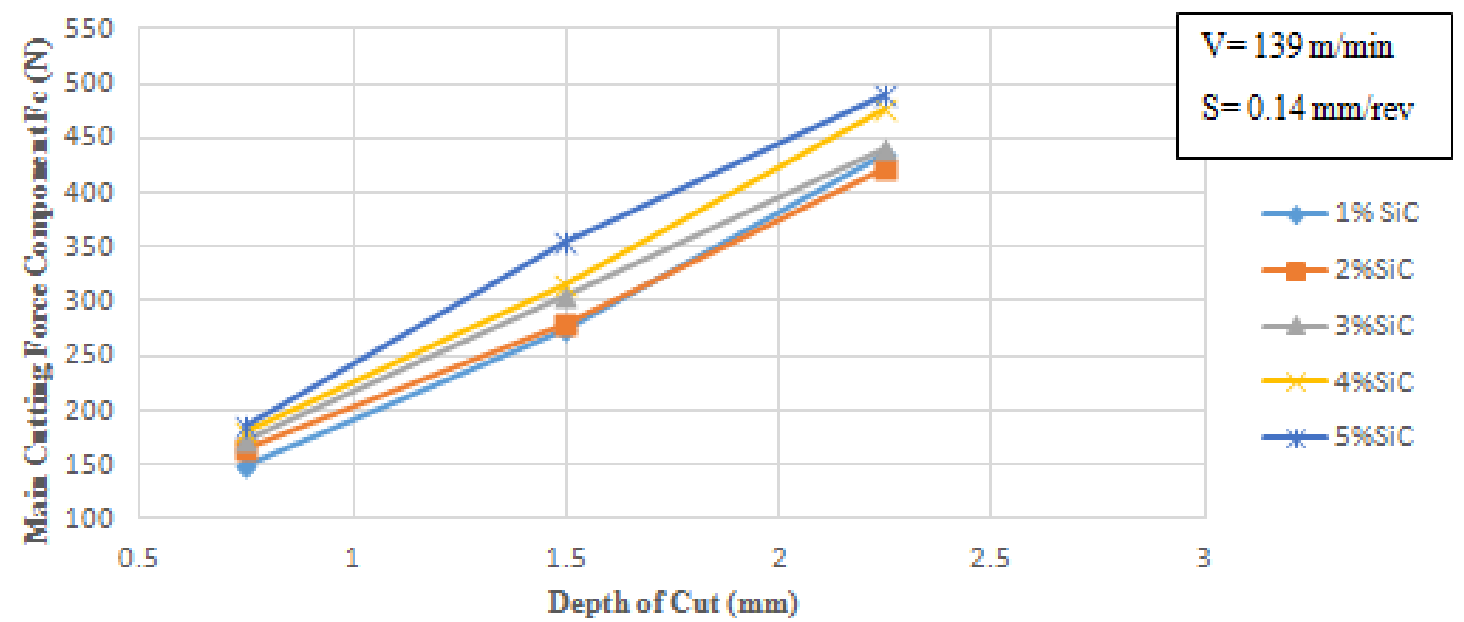

Figure 8. The influence of depth of cut on the main cutting force component.

Figure 8 shows the influence of depth of cut on the main cutting force component it can be noticed that the main cutting force component increases with the increase of depth of cut which arises from the increase of resistance to the tool 
path. It also can be noticed that this effect varies directly with the percent of $\mathrm{SiC}$ in the composite which is attributed to the increase in the content of the hard phase against the tool path. [4]

\subsection{Surface Roughness}

The effect of weight percentage of $\mathrm{SiC}$ nanoparticulates on surface roughness is shown in figure 9 , where it shows that the increase in weight percentage $\mathrm{SiC}$ nanoparticulates improved the surface finish, which is attributed to the increased hardness of nanocomposites.

Figure 8 shows the influence of cutting speed on surface roughness characteristic ( $\mathrm{Rz}$ ) during turning of $\mathrm{Al} / \mathrm{SiC}$ nanocomposite without use of coolant. The test results shows that the value of $\mathrm{Rz}$ are low at high cutting speed and comparatively high at low cutting speed. This is because increasing the cutting speed reduces friction which is consequently is reflected on the tool wear and thus surface roughness. Some times during turning, it can be observed that the value of surface roughness is abruptly higher than the trend value. The abrupt irregularity in the values of surface roughness may be due to the presence of clusters of hard abrasive nanoparticles.

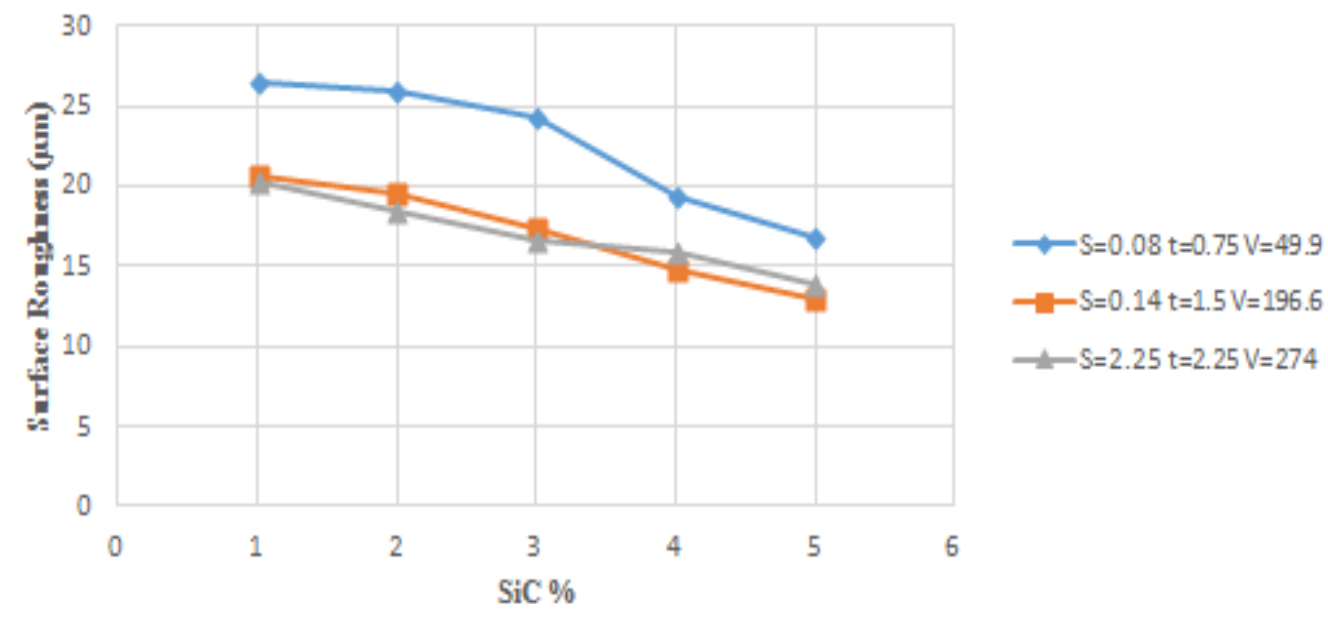

Figure 9. Shows the effect of weight percentage of SiC nanoparticulates on surface roughness

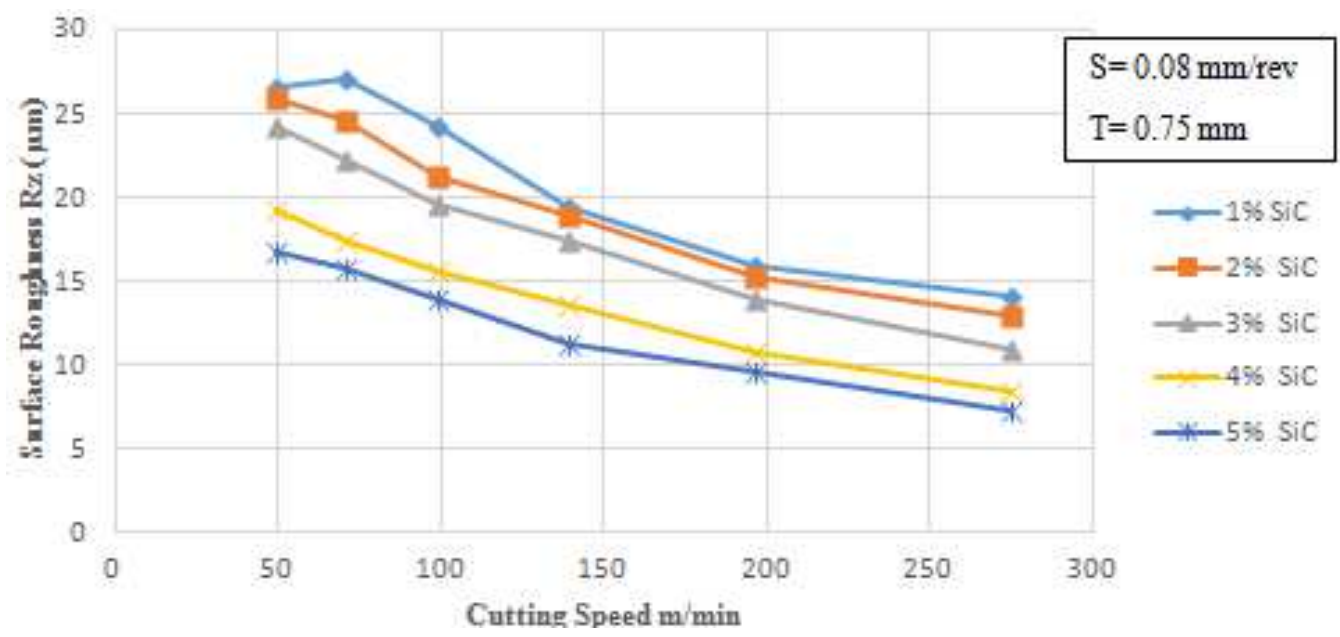

Figure 10. The influence of cutting speed on the Surface Roughness (Rz).

The influence of feed on surface roughness $\mathrm{Rz}$ is represented in figure 11. Experimental results showed that the surface roughness $\mathrm{Rz}$ increase by increasing feed rate. This is due to the widening in the area of contact and changes in the force per unit length, resulting in great distortion of chips. From the test results it can be concluded that when the feed increases from $0.08 \mathrm{~mm} / \mathrm{rev}$. to $0.2 \mathrm{~mm} / \mathrm{rev}$. ( nearly tripled) the value of surface roughness $\mathrm{Rz}$ is increased by $32 \%$, whereas when cutting speed is increased from 99 $\mathrm{m} / \mathrm{min}$ to $274.4 \mathrm{~m} / \mathrm{min}$ the value of $\mathrm{Rz}$ decreased by $47 \%$. 


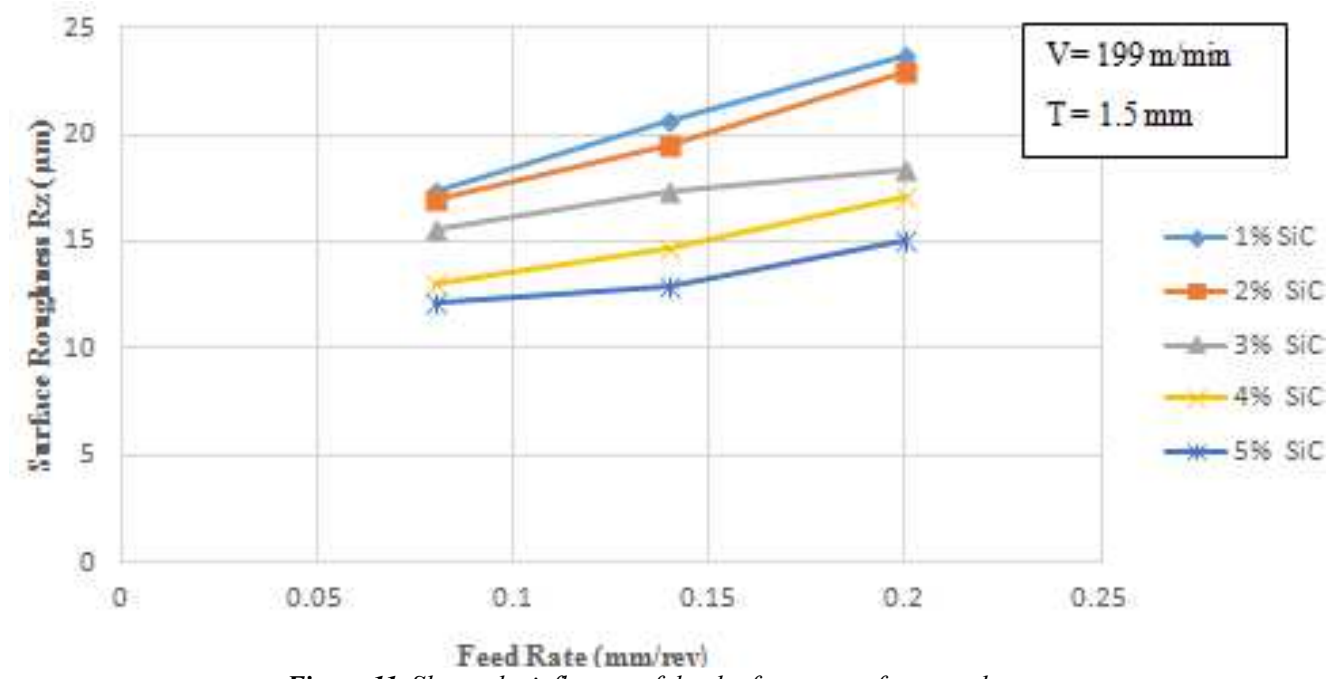

Figure 11. Shows the influence of depth of cut on surface roughness.

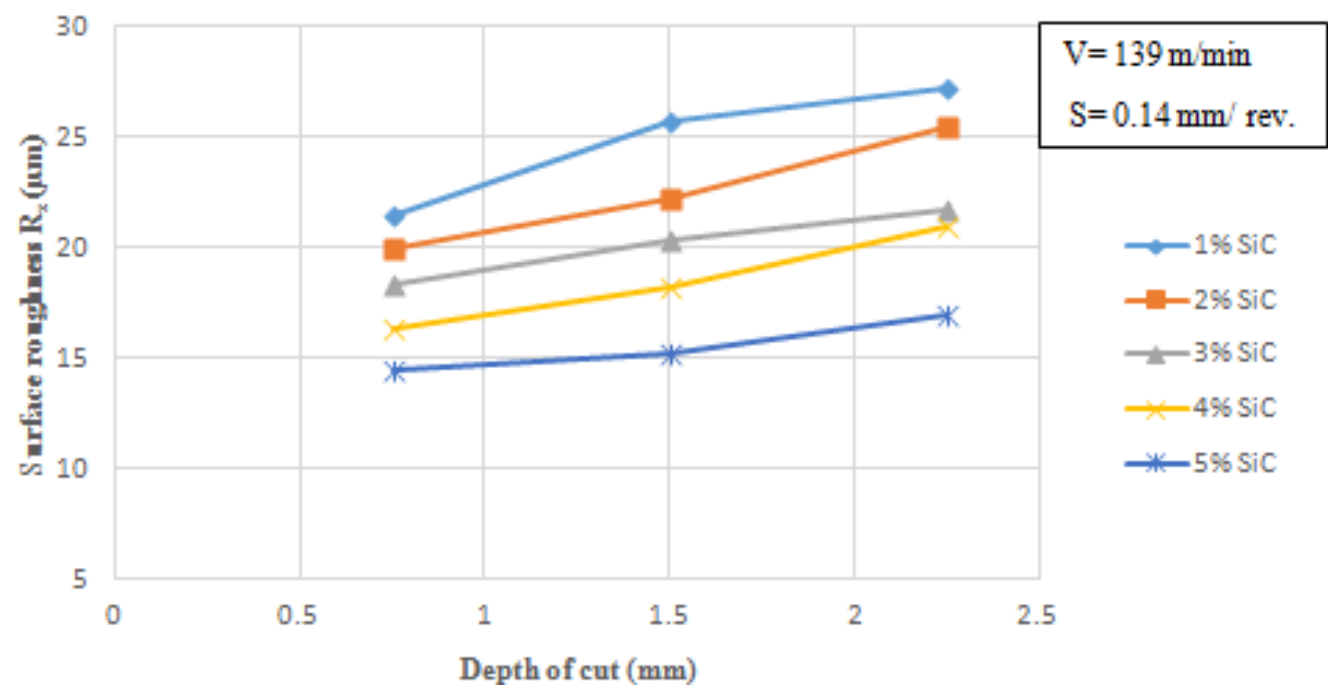

Figure 12. Shows the influence of depth of cut on surface roughness.

Figure 12 shows the influence of depth of cut on surface roughness. From these figure it can be observed that the increase in depth of cut decreases the quality of surface finish i.e. $\mathrm{Rz}$ increase by increasing depth of cut. This is because the increase in depth of cut increases the cutting forces and thus lead to a dynamic instability of the cutting process thus decrease the quality of surface finish. $[10,11]$

\subsection{Tool Wear}

The main wear pattern had been observed as regular flank wear. Figure 13 shows the effect of weight percentage of $\mathrm{SiC}$ nanoparticulates on flank wear. As expected, the flank wear increases with the increase in weight $\%$ of $\mathrm{SiC}$ nanoparticulates. These results were attributed to the increase in the weight fraction of reinforcement which increase the hard abrasive phase thus increase the number of abrasive particulates scratching the tool, so increases the tool wear [4, $10,11]$.

Figure 13 shows also the influence of cutting speed on the flank wear during turning of $\mathrm{Al} / \mathrm{SiC}$ nanocomposites. From the figure, it can be observed that when cutting speed is increases from $99 \mathrm{~m} / \mathrm{min}$ to $274.4 \mathrm{~m} / \mathrm{min}$ the flank wear goes up 2 times compare to its value at low speed. The effect of cutting speed on flank wear is, as cutting speed increases the rubbing area per unit time increase this gives more cutting area experienced by tool which will be one of the reasons for the increasing tool wear, also the heat generated at the interface between the tool and work piece is directly proportional to cutting speed that interfacial temperature soften the tool material which produces more wear.

\subsection{Chips Appearance}

Figure 14 shows the chips shapes formed during dry turning of $\mathrm{Al} / \mathrm{SiC}$ nanocomposite using carbide tools at constant cutting speed i.e. $99 \mathrm{~m} / \mathrm{min}$., feed $0.14 \mathrm{~mm} / \mathrm{rev}$. and depth of cut $1.5 \mathrm{~mm}$. From the test results it can be noticed that the type of chip changes from continues chip to discontinuous as the weight percentage of $\mathrm{SiC}$ nanoparticulates are increased from $1 \%$ to $5 \%$. These results are attributed to the increase of nanocomposite hardness with 
the increase of weight fraction of reinforcement.

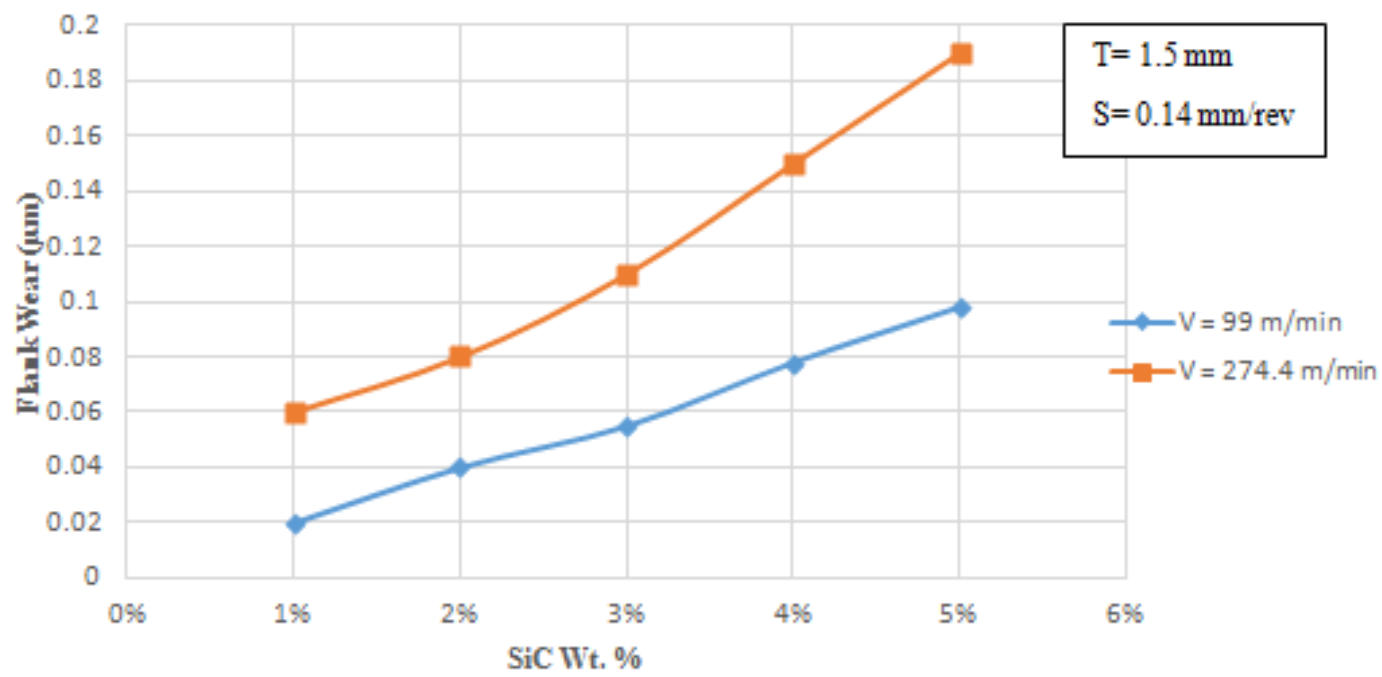

Figure 13. Shows the effect of weight percentage of SiC Nano particulates as well as the cutting speed on flank wear.

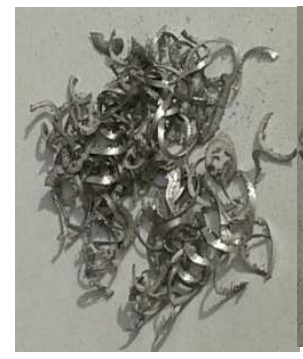

(a) $1 \%$

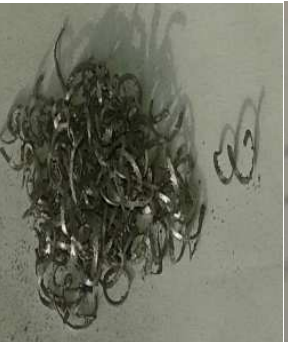

(b) $2 \%$

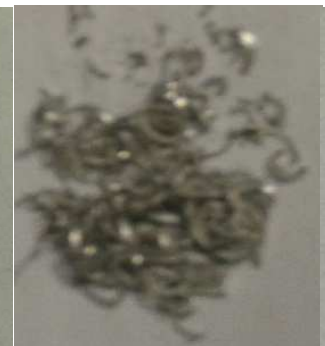

(c) $3 \%$

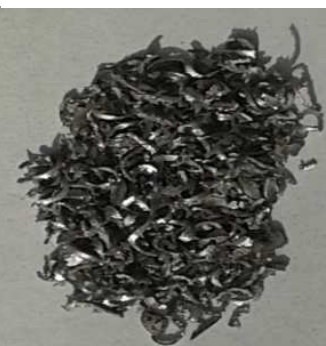

(d) $4 \%$

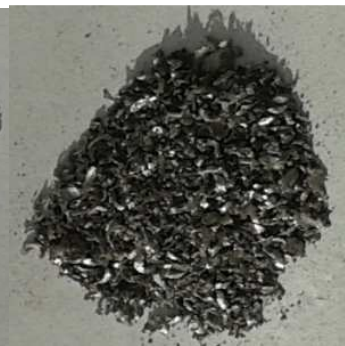

(e) $5 \%$

Figure 14. Shows the chips shapes formed during dry turning of Al/SiC nanocomposite.

\section{Conclusions}

According to the obtained results from the various tests we can conclude the following:

1. The hardness of the composites increase with the increase of the weight percent of $\mathrm{SiC}$ nanoparticulates which is attributed to the increase in the hard phase content in the ductile matrix.

2. The main cutting force component was increased by increasing the weight fraction of $\mathrm{SiC}$ nanoparticulates. Such behavior is attributed to the increased hardness of the nanocomposites which increases with increasing of weight percentage of $\mathrm{SiC}$ nanoparticulates. Moreover the main cutting force increased with increasing the feed rate due to the increase in contact area between the tool and work piece and thus the friction forces which are to be overcome by the tool. Also the main cutting force component was increased by increasing the depth of cut due to the increase of resistance to the tool path. However the main cutting force component was decreased by increasing the cutting speed due to the lack of formation of the B.U.E at high cutting speeds.

3. The surface roughness parameter $\mathrm{Rz}$ of $\mathrm{Al} / \mathrm{SiC}$ nanoparticulates was improved by increasing the cutting speed this is because increasing the cutting speed reduces the contact time between the tool and the work piece and thus reduces friction effect. Also the surface roughness parameter $\mathrm{Rz}$ was improved by increasing the weight fraction of the $\mathrm{SiC}$ nanoparticulates due to the increased hardness of nanocomposites.

4. The flank wear rate is high at low cutting speed due to the generation of high cutting forces and the formation of BUE. Also tool flank wear is high at high cutting speed Moreover increasing the weight fraction of $\mathrm{SiC}$ nanoparticulates increases the flank tool wear which arises from the increased of the hard phase content.

5. The machinability of $\mathrm{Al} / \mathrm{SiC}$ nanocomposites was improved by increasing the weight fraction of $\mathrm{SiC}$ nanoparticulates.

6. High speed, low feed and low depth of cut are recommended for machining of $\mathrm{Al} / \mathrm{SiC}$ nanocomposites.

\section{References}

[1] Luis, M. P., "MACHINING OF HYBRID COMPOSITES" $\mathrm{PhD}$. Thesis Faculty of Engineering - University of Porto 2005;

[2] Nikhilesh Chawla \& Yu-Lin Shen., "Mechanical Behavior of Particle Reinforced Metal Matrix Composites", Advanced Engineering Materials, Vol. 3 No. 6, 2001, PP. 357-370. 
[3] Payodhar, P \& Sachikanta, K., "A Novel route for development of Bulk Al/SiC Metal Matrix Nano Composites", Journal of Nanotechnology, Vol. 2011, 5 pages.

[4] A. Manna, B. Bhattacharayya., "A study on machinability of Al/SiC-MMC" Journal of Materials Processing Technology 2003, PP. 711-716.

[5] M. Z. Zahran, E. Y. El-Kady, M. H. Gheith, M. Abdel-Fattah., "Machinability of Nickel Particulates-Reinforced(AA6063) Aluminum Based Alloy"., Ain Shams University Scientific Bulletin Vol.42 No.1, 2007, PP. 777-796.

[6] E. Y El-Kady., "Machinability of Squeeze Casting MMCs A390 Reinforced with $\mathrm{SiC}$ and A12O3 Particulate" Scientific Bulletin of Ain Shams University, Faculty of Engineering, Vol. 38, No. 4 December 2003, PP. 867-886.

[7] Chambers AR, Stephens SE. "Machining of A1-5Mg reinforced with 5 vol.\% Saffil and 15 vol.\% SiC". Materials Science and Engineering; 1991, A135:287-90.
[8] S. BARNES and I. R. PASHBY., "Machining of Aluminum Based Metal Matrix Composites" Department of Engineering, University of Warwick, England, Applied Composite Materials, Vol. 2 1995, PP, 31-42.

[9] S. A. Sajjadi, H. R. Ezatpour \& M. Torabi Parizi., "Comparison of Microstructure and Mechanical Properties of A356 Aluminum Alloy/A12O3 Composites Fabricated by Stir and Compocasting Process" Materials and Design 34 (2012) PP. 106-111.

[10] E. Y El-Kady, T. S. Mahmoud \& M. H. G. Ghaith., "Machinability of A356/A12O3 Cast Aluminum Metal Matrix Nanocomposites (MMCs)", Material Science Vol. 9 Issue 1, 2013 PP. 1-7.

[11] Brintha. N. C., Shajulin B. and Winowlin Jappes J. T "Machining Parameter Optimization of $\mathrm{Al} / \mathrm{SiCp}$ Composite Materials Using Genetic Algorithm. International Journal of Engineering Research and Technology, Vol. 2 Issue 6 (2013), PP., 691-702. 